\title{
Melanoma de vagina
}

\section{Vaginal melanoma}
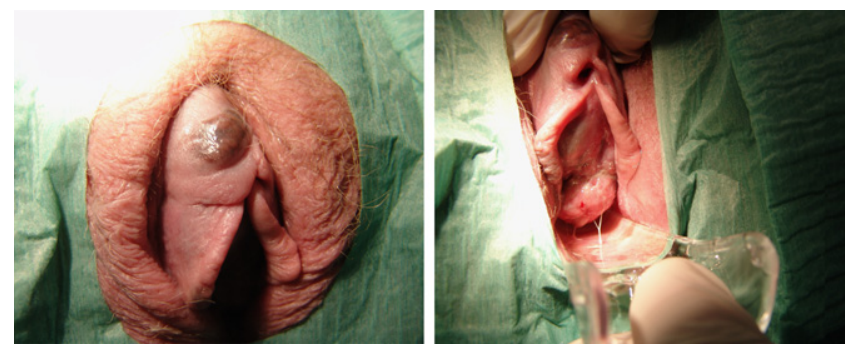

Figuras 1 y 2 - Masa en cara anterior de vagina, indurada de aspecto violáceo en alguna zona de consistencia firme, fija de aproximadamente unos 5-6 cm. extendiéndose por cara anterior de vagina y área vulvar. Se evidencia meato uretral parcialmente ocluido.
I. Fernández García*, L. Rodríguez Villamil,

I. González Rodríguez, R. Gil Ugarteburu,

J.R. Pérez-Carral García y V. Muruamendiaraz Fernández

Servicio de Urología, Hospital de Cabueñes, Gijón, Asturias, España

*Autor para correspondencia.

Correo electrónico: isabelfernandez81@hotmail.com

(I. Fernández García).

doi: 10.1016/j.acuro.2010.03.015

\section{Melanoma primario de uretra femenina}

\section{Primary melanoma of the female urethra}

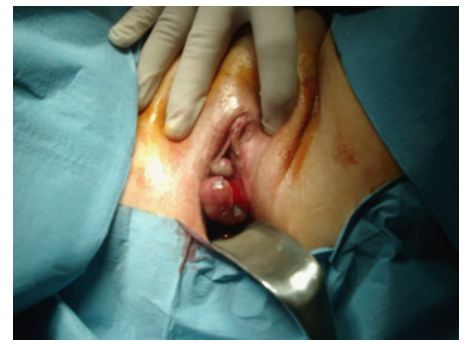

Figura 1 - Presencia de una masa vegetante ulcerada de unos $6 \mathrm{~cm}$. de diámetro y con tendencia al sangrado que dependía de la uretra.
C. Suárez Fonseca*, A. Maghnie Baydon y L. Gómez Tejeda

Servicio de Urología, Hospital Nuestra Señora de Sonsoles, Ávila, España

*Autor para correspondencia.

Correo electrónico: csfonseca@yahoo.es (C. Suárez Fonseca).

doi: 10.1016/j.acuro.2010.03.016 